\title{
Alianças em projetos complexos: um estudo de projetos do tipo EPC
}

\author{
Gabriel Del Bianco Madureira ${ }^{\mathrm{a}}$, Marly Monteiro de Carvalho ${ }^{\mathrm{a} *}$ \\ aniversidade de São Paulo, São Paulo, SP, Brasil \\ *marlymc@usp.br
}

\begin{abstract}
Resumo
0 objetivo deste trabalho é identificar os fatores críticos para o sucesso de projetos complexos, conduzidos por meio de alianças. Para tal, foi elaborado um quadro teórico alicerçado em conceitos relacionados a projetos e parcerias, que abordou aspectos relacionados à motivação, caracterização e dinâmica de funcionamento. A pesquisa de caráter exploratório foi realizada em uma organização da área de serviços de engenharia, utilizando métodos de pesquisa qualitativos e quantitativos. Foram coletados dados de 11 projetos em parceria e entrevistados 43 gerentes envolvidos em projetos desse tipo. A triangulação da revisão de literatura com as evidências de campo permitiu destacar alguns fatores críticos na condução de alianças em projetos do tipo Engenharia, Aquisições e Construção (Engineering, Procurement and Construction - EPC). Os resultados para cinco fatores que apresentaram forte correlação: cooperação, confiança, troca de informações, sinergia, grau de integração. Além disso, foi possível verificar que dos 17 fatores, 12 tiveram relação com o resultado do projeto, em alguma das dimensões estudadas.
\end{abstract}

Palavras-chave

Aliança. Gestão de projetos. Cooperação. Projetos complexos. EPC.

\section{Introdução}

0 número de parcerias tem crescido, estima-se que um terço das receitas das 2000 maiores empresas dos Estados Unidos e União Europeia venham de parcerias (Holmberg \& Cummings, 2009). Mas por volta de setenta por cento dessas parcerias ainda resultam em fracasso (Lyra, 2005).

As empresas precisam entender a dinâmica da rede de parcerias, para poder escolher seus caminhos na rede ao invés de simplesmente aceitá-los (Gulati, 1998). Além disso, saber escolher o parceiro e as características da parceria é fundamental para operar em um ambiente rico em parcerias como o da empresa analisada (Holmberg \& Cummings, 2009).

Também no ambiente de projetos, observa-se importante crescente do tema de parcerias, em especial no desenvolvimento de projetos complexos como refinarias, portos, aeroportos ou complexos industriais. 0 desenvolvimento desses projetos gera um grande risco tanto para o cliente quanto para o contratado em função da complexidade e do risco econômico envolvido (Loots \& Henchie, 2007). Como o atual cenário é de crescimento econômico e de expansão de infraestrutura no País, a demanda por esse tipo de projeto está aquecida, surgem novas possibilidades de parceria a todo o momento. No entanto, por vezes, parcerias ad hoc feitas para abraçar uma oportunidade de negócio, depois de contratadas devem ser efetivadas, o que não é uma tarefa fácil.

Nesse contexto, este trabalho pretende identificar os fatores críticos para o sucesso de projetos complexos, conduzidos por meio de alianças. A abordagem utilizada mesclou instrumento de pesquisa qualitativa e quantitativa em um estudo de caso realizado em uma empresa de engenharia. Foram acompanhados os resultados de 11 projetos e entrevistados 43 gerentes envolvidos em projetos desse tipo.

Este artigo está estruturado em cinco seções. A sintese da revisão de literatura é apresentada na seção 2, são explorados os principais aspectos relacionados 
a parcerias. A seção 3 apresenta o detalhamento da abordagem metodológica utilizada na pesquisa. Os resultados da pesquisa são apresentados e discutidos na seção 4, seguidos das conclusões na seção 5.

\section{Parceria em projetos: síntese da literatura}

0 desenvolvimento de projetos complexos em geral envolve várias organizações quer por demanda dos contratantes, por regras dos processos de licitação para mitigar o risco, quer por estratégia e conveniência dos parceiros. Para Pauget \& Wald (2013), redes de projetos grandes e complexos são caracterizadas pela colaboração de organizações e indivíduos heterogêneos, com habilidades complementares e competência relacional. Corroboram com essa visão Morris \& Geraldi (2011), que propõem que o gerenciamento de projetos deve focar a criação das condições para apoiar e fomentar projetos, tanto em sua organização-mãe quanto em seu ambiente externo e seus relacionamentos.

Cada vez mais termos como Engineering, Procurement and Construction (EPC) e Engineering, Procurement and Construction Management (EPCM) vão se popularizando.

A forma de contratação de projetos complexos, também denominados empreendimentos, têm variado bastante ao longo dos anos. As empresas, bancos, financiadoras e seguradoras, envolvidas com esse tipo de projeto, buscaram formas de mitigar risco alto, evitando que o projeto todo fique sob responsabilidade de uma empresa. Por outro lado, esse tipo de projeto demanda uma gama tão variada de competências, que dificilmente pode ser atendido por uma única empresa.

$\mathrm{Na}$ busca por equipes mais especializadas e pela mitigação do risco, foi que surgiu a contratação desse tipo de projeto: "Engineering, Procurement and Construction"(EPC). Nesse tipo de contratação, a empresa cliente contrata uma empresa para realizar todas as etapas de engenharia, construção, comissionamento e montagem de equipamentos. Adicionalmente, costuma-se incluir também o gerenciamento do empreendimento. Para a realização do projeto, o cliente especifica as características básicas como os locais de realização e as principais variáveis de entrada e saída. Normalmente, especifica-se também a tecnologia a ser utilizada que pode ou não ser fornecida por uma terceira empresa. No caso em que é o EPCista (nome usual da empresa contratada para fazer o projeto em EPC) que detém a tecnologia ou que é responsável por contratar a empresa de tecnologia, ele passa a se responsabilizar por essa tecnologia. Nesse caso, têm-se o EPC conhecido como EPC “Turn-Key” (Loots $\&$ Henchie, 2007). 0 EPC traz um risco menor para o cliente, uma vez que esse risco é transferido para a empresa contratada, que, em geral, também cobra um prêmio de preço (ver Figura 1a). Essa transferência é feita através de cláusulas contratuais com multas aplicadas por atraso ou por não atingir os parâmetros técnicos indicados.

Depois de um grande movimento de subcontratação dos projetos nos moldes de contratação EPC, observou-se em alguns casos maior necessidade de controle da execução do empreendimento por parte da empresa cliente. Assim surgiu o EPCM que é uma forma intermediária entre o tipo tradicional e o tipo EPC.

0 EPCM é um serviço profissional que altera a divisão de risco em relação ao EPC (Loots \& Henchie, 2007). A diferença principal do EPCM para o EPC é que o risco continua com o cliente uma vez que a empresa de EPCM apenas realiza as compras e faz a gestão em nome do cliente. Assim, a responsabilidade técnica é do cliente e não da empresa de EPCM, diminuindo muito seu risco. A empresa que realiza

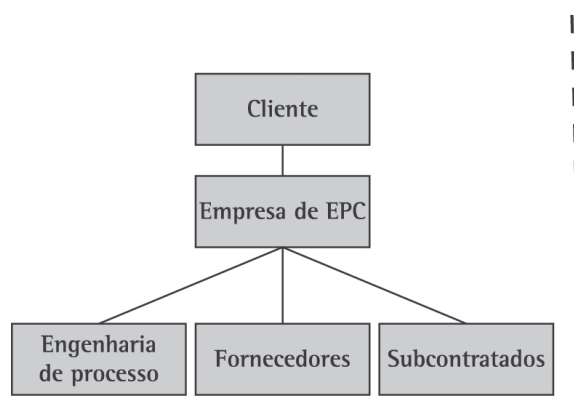

EPC

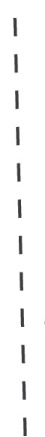

I

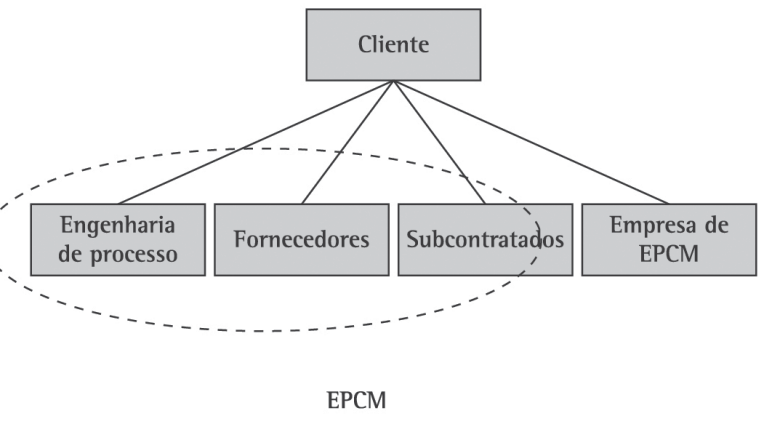

EPCM

Figura 1. Estrutura de Funcionamento do EPC versus EPCM (Adaptado de Loots \& Henchie, 2007). 
o EPCM tem suas responsabilidades mais ligadas a prazos e à gestão do projeto, não sendo responsável por realizar a construção, apenas monitorá-la em nome do cliente. 0 cliente por sua vez, passa a controlar melhor o projeto e zela pelos padrões de qualidade que deseja, o que não necessariamente ocorre no EPC (ver Figura 1b). A Figura 1 apresenta as estruturas do EPC e do EPCM.

Existem várias formas de pagamento que podem ser realizadas pelo cliente e esta influencia o projeto significativamente uma vez que altera a competição entre cliente e contratado no que diz respeito ao resultado. Basicamente, os valores dos EPC e EPCM podem ser pré ou pós-estabelecidos.

As formas mais convencionais de contratação em projetos (EPC e EPCM) inibem a comunicação direta e aberta entre cliente e fornecedor uma vez que seus resultados dependem sempre da desconfiança um do outro (Henneveld, 2006). De um lado, o EPCista tenta sempre superestimar os dados de forma a poder obter uma margem maior e, de outro, o cliente, por sua vez, tenta forçar os preços e condições para baixo, melhorando sua condição, mas prejudicando a rentabilidade do EPCista.

Existem muitos riscos aliados a esses projetos e muitas vezes os clientes e contratados se confrontam tentando distribuir esse risco entre si. Na contratação EPC, o cliente paga um prêmio de preço para o contratado assumir o risco. No contrato EPCM, o cliente mantém o risco, mas diminui sua intensidade contratando uma empresa para gerenciar o projeto. Essa disputa entre cliente e contratado, seja por lucratividade seja para dividir o risco, pode prejudicar o resultado do projeto de forma significativa, pois nenhum dos dois está realmente comprometido com o melhor para o projeto (Guedes et al., 2008).

Visando lidar melhor com essa questão de disputa entre as partes, surgiu o contrato tipo "aliança" (Alliance Contracting). Esse contrato está baseado em um relacionamento de "[...] igualdade, confiança, respeito, abertura, sem disputas e acusações [...]" (Henneveld, 2006, p. 4). Assim, busca-se estabelecer uma relação "ganha-ganha" entre cliente e contratado. Para o funcionamento desse tipo de contrato é necessário trabalhar com total transparência ("livro aberto") uma vez que os parceiros e o cliente têm que ter livre acesso às estimativas de custo realizadas para que a confiança se estabeleça.

\subsection{Parcerias}

As parcerias têm sido estudadas pela literatura de forma muito extensiva. Elas podem ocorrer em função de vários motivos, podem ter várias configurações e ocorrer em fronteiras verticais e horizontais (Gulati, 1998).

Existem vários motivos para realização de parcerias na literatura como gerar economia de escala, aprender novas competências com o parceiro, dividir custos e riscos, compartilhar recursos e diminuir as barreiras de entrada e saída em um mercado (Kogut, 1988; Harrigan \& Newman, 1990; Lorange et al., 1992; Gulati \& Singh, 1998; Amato Neto, 2000; lreland et al., 2002; Lyra, 2005; Wu et al., 2009).

Doz \& Hamel (1998) indicaram três principais motivos para a entrada em uma parceria: coopção, coespecialização e o aprendizado. A coopção é a possibilidade de ganhar força competitiva com os rivais, a coespecialização é quando a sinergia entre os recursos complementares das organizações contribui para a aquisição de conhecimentos únicos. Já o aprendizado aumenta as habilidades e conhecimentos da empresa. Assalim \& Almeida (2013) ressaltam ainda a importância da estrutura de aprendizagem organizacional sistêmica para a cooperação institucional como crítica para o sucesso de EPCs, devido ao longo ciclo de vida do projeto.

Já Kogut (1988) e Holmberg \& Cummings (2009) dividem as motivações para entrada em uma parceria em cinco categorias: custos transacionais, recursos, posicionamento estratégico, aprendizado e outras motivações, por exemplo, a redução de risco. Wu et al. (2009) reforçam a busca por recursos complementares entre parceiros. Enquanto outros autores destacam a questão do aprendizado (1reland et al., 2002; Kogut, 1988).

Parceria pode ser definida como uma forma de relacionamento entre empresas, que optam por realizar uma operação conjunta, compartilhando recursos e conhecimentos ao invés de operarem individualmente (Dussauge et al., 2004).

Para Lorange et al. (1992), existem quatro tipos básicos de parceria, conforme Tabela 1: a "Parceria Ad Hoc" ("Ad hoc Pool”), o "Consórcio", a "Joint Venture" (JV) baseada em projeto e a "Joint Venture Madura" ( "Full-blown Joint Venture").

$\mathrm{Na}$ parceria ad hoc, os parceiros investem o mínimo de recursos complementares, em uma base temporária, sendo todo o resultado (de aprendizagem, know-how, equipamentos, lucro, etc.) retirado sem reinvestir. No "consórcio", os parceiros estão dispostos a colocarem mais recursos e têm uma visão mais a longo prazo do que no caso ad hoc, mas, na saída, os resultados são enviados aos parceiros. Ambas as "JV" retêm os resultados provindos da parceria. A "JV baseada em projeto" tem uma visão mais de curto prazo, temporária, avançando à medida que é necessário. A “JV madura” é a mais forte das parcerias, 
Tabela 1. Tipos de parceria.

\begin{tabular}{|c|c|c|c|}
\hline & & \multicolumn{2}{|c|}{ Entrada de Recursos } \\
\hline & & Apenas o necessário para o curto prazo & $\begin{array}{l}\text { Todo o necessário para a } \\
\text { operação de longo prazo }\end{array}$ \\
\hline \multirow{2}{*}{ 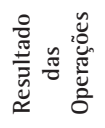 } & $\begin{array}{l}\text { Fica com os } \\
\text { Parceiros }\end{array}$ & Parceria ad hoc & Consórcio \\
\hline & $\begin{array}{c}\text { Fica retido na } \\
\text { Parceria }\end{array}$ & Joint venture Baseada em Projeto & Joint Venture Madura \\
\hline
\end{tabular}

Fonte: Adaptado de Lorange et al. (1992, p. 11).

os recursos são fornecidos em abundância e a maior parte dos resultados retorna para a própria aliança uma vez que seus parceiros reinvestem os recursos necessários na JV no longo prazo.

Guerrini \& Vergna (2011) propõem um modelo de atores e recursos para auxiliar a formação de redes de cooperação em obras de edificações, que representa os relacionamentos interorganizacionais, as responsabilidades de cada ator envolvido e o processo de ciclo de vida da rede.

Segundo Hoffmann (2007), há três tipos de estratégia em uma parceria: adaptação, flexibilidade e estabilização. Se a parceria é feita para poder se adaptar a uma necessidade ambiental, como a necessidade de expansão ou de obtenção de recursos, denomina-se de estratégia de adaptação. Se a parceria é uma forma de aumentar a flexibilidade para as mudanças que podem vir a ocorrer no ambiente, denomina-se de estratégia de flexibilidade. Finalmente, a estratégia de estabilização serve para explorar os recursos atuais de forma a obter acesso a novos mercados.

As parcerias podem ser em um extremo, uma simples divisão de tarefas entre os envolvidos, não havendo praticamente interfaces críticas, e, no outro, um ambiente interdependente, em que os envolvidos necessitam controlar e acompanhar o trabalho do outro de perto e regularmente. Quanto maior a interdependência entre os parceiros, maior serão os custos de coordenação (Gulati \& Singh, 1998).

Nesse contexto, é definida a interdependência entre organizações como uma "[...] situação em que uma organização tem recursos ou competências benéficas que não são possuídas pela outra [...]" (Gulati, 1995, p. 621).

A interdependência pode ser dividida em três categorias: generalizada, sequencial e recíproca. A generalizada ocorre quando cada parte auxilia no todo e vice-versa, agregando recursos para alcançar seus objetivos e gerando benefícios comuns através da aplicação de investimentos comuns. A sequencial ocorre quando as atividades dos parceiros são separadas e sequenciais, havendo maior necessidade de coordenação para a realização das tarefas. A recíproca ocorre quando os produtos produzidos por cada parceiro são os mesmos, o que demanda ajuste mútuo e a contínua adaptação, havendo grande necessidade de comunicação e de planejamento conjunto (Gulati \& Singh, 1998). Reforçam a necessidade de comunicação e planejamento, os estudos de Narayanan et al. (2011), que examinaram 182 projetos de software desenvolvidos na Índia no formato outsourcing e concluíram que, quando a capacidade de planejamento é alta, a estabilidade da equipe e a eficácia da comunicação impactam positivamente o desempenho do projeto. Sun \& Zhang (2011) destacam o papel de mecanismos de coordenação interfuncional e interprofissional no contexto de megaprojetos de construção, pois estabelecem uma boa comunicação, criando unidade e cultura de cooperação e parceria em projetos. No contexto brasileiro, De Britto Pires et al. (2013) analisaram o Centro de Excelência (CE) em Engenharia, Procurement and Construction (EPC), uma organização híbrida que reúne empresas de petróleo, empresas de EPC, universidades e escolas técnicas, entidades governamentais, associações profissionais e entidades da indústria. A pesquisa identificou barreiras relacionadas à fraca cultura de colaboração e alta assimetria entre os membros da rede.

Já para Dabholkar \& Neely (1998), as interdependências podem ser divididas em três dimensões básicas: temporal, orientação aos objetivos e balanços de poder, formando o cubo da interdependência. $\mathrm{Na}$ dimensão temporal, a interdependência pode ser de curto prazo ou de longo prazo. Na dimensão de orientação de objetivos, existem interdependências competitivas (um parceiro ganha e o outro perde) ou cooperativas (os dois ganham). Já quanto ao Balanço de poder, os níveis são: poder balanceado e desbalanceado.

Ragan \& Yoshino (1996) apresentam uma tipologia que pode ser utilizada para caracterizar as alianças em função do tipo de interação e do conflito em potencial. 0 nível de interação (alto, baixo) e o conflito em potencial (alto, baixo) que pode existir entre os parceiros influem diretamente na decisão entre cooperar e competir, gerando quatro tipos de parcerias: pré-competitiva (alto conflito e baixa interação), competitiva (alto conflito e alta interação), pró-competitiva (baixo conflito e baixa interação) e não competitiva (baixo conflito e alta interação). 
Parcerias com alto conflito em potencial acabam tendo um ambiente propício para a competição entre os parceiros. E essa competição acaba sendo mais acirrada com o aumento do nível de interação entre eles (Ragan \& Yoshino, 1996).

É a proporção desses benefícios que determina o quão competitivo ou cooperativo serão os parceiros de uma parceria. Como "[...] a variedade de oportunidades que existem fora da parceria de cada uma das empresas é o que determina o comportamento na parceria [...]" (Khanna et al., 1998, p. 194), as empresas não devem buscar apenas obter benefícios, mas devem analisar quais benefícios obter em função do escopo relativo (relative scope), que pode ser definido como "[...] o raio de escopo da parceria no total dos mercados nos quais a empresa está ativa [...]" (Khanna et al., 1998, p. 195). 0 escopo relativo é único para cada empresa em cada parceria. Quanto maior o escopo relativo, maiores são as oportunidades de aplicação desse benefício para essa empresa fora da parceria.

As empresas que constituem uma parceria possuem características como porte, idade e recursos financeiros distintos e esses são fatores que influenciam na entrada ou não em parcerias (Gulati, 1995). Assimetrias entre os parceiros de uma parceria podem influenciar significativamente seus resultados, pois uma empresa maior costuma ter mais mercados do que uma menor e, portanto, acaba tendo um escopo relativo maior (mais locais para aplicar os aprendizados fora da parceria) do que a outra. Além disso, o porte da empresa influi diretamente no poder de barganha, o que permite que obtenha mais benefícios (Khanna et al., 1998). Desta forma, o balanço de poder financeiro ou de influência entre os parceiros influencia diretamente as decisões tomadas pela parceria (Dabholkar \& Neely, 1998).

Além disso, surgem questões de como serão rateados esses resultados, sejam bons ou ruins entre os parceiros. Para a realização dessa divisão, entra em jogo o poder de barganha de cada um dos parceiros e os seus objetivos (Harrigan \& Newman, 1990).

Há três tipos básicos de cooperação quanto ao resultado: sinergia, nivelamento e impacto reverso-negativo ( "negative reverse-impact"). A sinergia é o aumento de valor em função da troca de experiências e de "know-how". 0 nivelamento é a capacidade que se tem de aumentar o valor da informação recebida com o aprendizado e o impacto reverso-negativo ocorre quando o uso do conhecimento por uma das partes reduz o valor da outra parte, prejudicando a cooperação. Assim, as empresas só compartilham conhecimento quando há forte sinergia e fraco nivelamento (Levy et al., 2003).

Desta forma a confiança (trust) entre as empresas envolvidas na parceria é um aspecto-chave, em que se pressupõe que o parceiro não irá explorar as vulnerabilidades do outro (Gulati, 1998). No entanto, muitas vezes o comportamento oportunista se manifesta na parceria. Reame Junior \& Amaral (2012) também destacaram a importância da confiança em projetos colaborativos de novos produtos no setor de máquinas agrícolas, mas destacam também outros fatores críticos para o sucesso: comprometimento, aprendizado documentado e continuidade de equipes. Já Albertin \& Amaral (2010) ressaltaram aspectos relacionados ao contexto da parceria, em especial (identificação de parceiros, diferença cultural, igualdades e influências externas).

Considerações sobre confiança são importantes para se estabelecer normas de bom senso e de igualdade entre os parceiros, tornando a parceria mais previsível. lsso é fundamental, pois em função do risco associado a essas parcerias e seu impacto nos projetos, os parceiros ficam muitos expostos entre si. Por isso, os parceiros devem confiar uns nos outros e valorizar a análise de reputação de mercado das empresas envolvidas (Gulati, 1998, 1995).

\subsection{Seleção de parceiros}

Alguns modelos de seleção dos parceiros foram propostos pela literatura. Por isso é importante aprender a desenvolver as competências relacionais, pois elas auxiliam no processo de estruturação de futuras parcerias, prevendo investimentos e esforço para mapear, selecionar, discutir e analisar as lições aprendidas em parcerias (Zollo et al., 2002).

Holmberg \& Cummings (2009) propõem um processo de seleção de parceiros baseado em 4 etapas. $\mathrm{Na}$ etapa 1, os objetivos da corporação como um todo devem ser alinhados e desdobrados em objetivos para a parceria, evitando problemas no que diz respeito ao desalinhamento futuro da parceria com a corporação. $\mathrm{Na}$ etapa 2, são definidos os fatores críticos de sucesso para essa parceria, sendo que sem eles não é possível sua realização. Na etapa 3 , devem ser mapeados todos os possíveis parceiros para que possa ser feita a seleção, o que demanda um grande acesso a informações do mercado. Na etapa 4, esses parceiros são comparados e a escolha do parceiro é feita com base no enquadramento aos objetivos e fatores críticos de sucesso, e com maior possibilidade de interação (Gulati, 1995). Holmberg \& Cummings (2009) propõem uma ferramenta para essa etapa, baseada na ponderação dos critérios relacionados aos fatores críticos de sucesso e pontos relacionados às características específicas aos parceiros analisados.

Dentro de um ambiente EPC, é necessário introduzir fatores contextuais dentro dos critérios de seleção, 
que, segundo Masi et al. (2013), podem ser agrupadas em dois macrofatores: o grau de dificuldade em gerir e o impacto sobre o projeto.

Brouthers et al. (1995) propõem um método com quatro fatores básicos que devem ser buscados nos parceiros: habilidades complementares, culturas cooperativas, objetivos compatíveis e bons níveis de risco. Inicialmente devem-se buscar exaustivamente parceiros de modo a selecionar aqueles que possuem maior habilidade complementar (interdependência). A cultura de cooperação é o fator analisado, busca-se minimizar diferenças e maximizar o relacionamento direto entre os executivos dos parceiros envolvidos, tornando o ambiente mais propício à cooperação, diminuindo a rivalidade. Os objetivos compativeis entre os parceiros aumentam o desempenho geral da parceria bem como evitam divergências de ideias. A mensuração dos níveis de risco da parceria traz a segurança necessária entre os parceiros para que possa surgir cooperação segura.

Quando se faz uma seleção de parceiro é importante ter em mente que, durante a primeira experiência, é comum ocorrerem vários problemas e dificuldades de comunicação. Ao trabalhar nos detalhes operacionais de uma parceria, os parceiros desenvolvem melhor entendimento de seus parceiros, seja da cultura, dos sistemas de administrativos, capacidades ou fraquezas. As experiências prévias constroem confiança entre os parceiros ao longo do tempo, além de criar rotinas que facilitam a interação (Zollo et al., 2002). Por outro lado, quanto maior for o número de parcerias com um mesmo parceiro menor será a probabilidade de novas parcerias conjuntas; isso ocorre principalmente porque depois de várias parcerias, a quantidade e qualidade dos benefícios privados que podem ser obtidos com o mesmo parceiro diminuem (Gulati, 1995).

Por outro lado, em função da complexidade da união entre duas ou mais empresas com características distintas, muitas vezes ocorre um significativo aumento da carga administrativa envolvida. Além disso, quando a comunicação e o alinhamento entre as partes não estão bem ajustados, surgem pontos e sobreposição de tarefas, em que cada parceiro realiza algo em repetição ou sem compartilhar com o parceiro (Henneveld, 2006).

Para que a evolução da parceria leve a um sucesso é necessário trabalhar sempre aprendendo, renegociando e reavaliando a parceria de modo a mantê-la sempre equilibrada, atendendo os requisitos dos parceiros. Para isso, é necessário que os parceiros possuam grande capacidade de adaptação e que haja um bom ambiente para o diálogo (Ariño \& de la Torre, 1998).

0 sucesso de uma parceria pode ser explicado por três correntes básicas: a visão baseada em recursos, a visão baseada em competências e a visão baseada em fatores relacionais (Wittmann et al., 2008). A visão baseada em recursos enfatiza a importância dos recursos da organização e é em função da heterogeneidade desses recursos entre as organizações que uma obtém melhor desempenho do que a outra. Assim, o sucesso da parceria depende dos recursos de cada parceiro e de suas capacidades de criação de novos recursos (Wittmann et al., 2008). A visão baseada em competências é uma extensão lógica da visão baseada em recursos, pois as competências são "[...] a habilidade de sustentar e coordenar o desenvolvimento de ativos de modo a ajudar a empresa a atingir suas metas [...]" (Wittmann et al., 2008 p. 3). Assim, para obter o sucesso na parceria, a empresa deve desenvolver a competência de realizar parcerias. A visão baseada em fatores relacionais sugere que o sucesso está baseado em fatores relacionais como a confiança (trust), comprometimento, cooperação e comunicação. Assim, terá sucesso aquela parceria que conseguir aprimorar esses fatores de forma completa. Essas visões são complementares (Wittmann et al., 2008) e devem ser tomadas na sua totalidade ao analisar o sucesso em uma parceria.

Segundo Gulati (1998), dado o objetivo multifacetado de várias parcerias, o desempenho pode ser difícil de se medir através de indicadores financeiros. Além disso, muitas vezes esse desempenho é assimétrico entre os parceiros, uma vez que uma empresa pode chegar a seus objetivos, mas a outra não. Como em muitas parcerias os parceiros têm objetivos distintos com a parceria, o sucesso deve ser avaliado individualmente em função dos objetivos de cada empresa.

Com base nesta revisão de literatura, as principais variáveis foram identificadas e referências foram identificadas, conforme síntese da Tabela 2.

\section{Métodos de pesquisa}

Dado o caráter exploratório da pesquisa adotou-se uma abordagem combinada, qualitativa e quantitativa.

A etapa inicial da pesquisa foi a de revisão de literatura para a construção do Quadro Teórico, conforme sugerido por Voss et al. (2002). A pesquisa bibliográfica pautou-se na busca de artigos nas bases científicas disponíveis no Portal de Periódicos da Capes, que resultou em artigos de vários periódicos e permitiu identificar as principais variáveis relacionadas ao tema (ver Tabela 2).

A pesquisa de campo foi desenvolvida em uma empresa de engenharia. Os critérios de seleção foram: a importância estratégica da atividade de projeto para a organização, o desenvolvimento de projetos complexos do tipo EPC, conduzidos em parcerias com 
outras empresas, além do acesso dos pesquisadores aos dados de projeto (relatórios de desempenho e outros documentos) e aos stakeholders-chave dos projetos.

Esse levantamento se deu em duas etapas, a primeira coletou dados já existentes na empresa que caracterizassem os projetos, parceiros e outras características que pudessem interessar a este trabalho. Várias fontes de evidências foram utilizadas, como os registros disponíveis no sistema informatizado de gerenciamento de projeto da empresa; entrevistas com membros do escritório de gestão de projetos (PMOProject management Office) e gerentes dos projetos.

Para a primeira etapa, foram utilizadas as apresentações das reuniões de abertura, fechamento e acompanhamento dos projetos do sistema de gerenciamento da empresa. Além disso, foram utilizados dados de um painel de indicadores, existente na empresa, cujos projetos são analisados mensalmente pelo Escritório de Gestão de Projetos ("Project Management Office"- PMO). Entrevistas pontuais com algumas pessoas-chave da organização também foram utilizadas como forma de validar e complementar os dados obtidos.
Com base nesse acesso inicial aos dados, foi feita uma seleção dos projetos que atendiam aos critérios da pesquisa, i.e., eram do tipo EPC. Do portfólio analisado, composto de 99 projetos, 22 indicaram algum tipo de parceria e 11 foram selecionados para compor a amostra do trabalho.

$\mathrm{Na}$ segunda etapa, foram feitas entrevistas e um levantamento tipo "survey" com profissionais de cada projeto analisado por meio de um questionário, conforme será detalhado na sequência.

\subsection{Amostra e perfil dos entrevistados}

$\mathrm{Na}$ etapa inicial da pesquisa, foram realizadas entrevistas com diretores e membros do PMO para compreensão do contexto organizacional e de projetos.

Para a segunda etapa, que tinha como objetivo abranger um conjunto maior de stakeholders envolvidos em projetos do tipo EPC, os respondentes foram selecionados visando obter opiniões de pessoas do nível 1 e 2 da hierarquia do projeto, representada na Figura 2.

Tabela 2. Síntese das variáveis e respectivas referências.

\begin{tabular}{|c|c|}
\hline VARIÁVEL & REFERÊNCIAS \\
\hline MOTIVAÇÃO DE ENTRADA & (Gulati, 1998; Ireland et al., 2002; Khanna et al., 1998) \\
\hline CULTURA ORGANIZACIONAL & (Brouthers et al., 1995; Ozorhon et al., 2008) \\
\hline METODOLOGIA & (Ozorhon et al., 2008) \\
\hline SINERGIA & (Ariño, 2003; Lyra, 2005; Ozorhon et al., 2008) \\
\hline GRAU DE INTERAÇÃO & (Dabholkar \& Neely, 1998) \\
\hline BALANÇO DE PODER & (Anselmo, 2005; Dabholkar \& Neely, 1998; Harrigan \& Newman, 1990; Khanna et al., 1998) \\
\hline COMPLEMENTARIDADE & (Ariño, 2003; Brouthers et al., 1995; Ireland et al., 2002) \\
\hline COOPERAÇÃO & $\begin{array}{c}\text { (Anselmo, 2005; Ariño, 2003; Brouthers et al., 1995; Dabholkar \& Neely, 1998; Gulati, 1995; } \\
\text { Harrigan \& Newman, 1990; Khanna et al., 1998) }\end{array}$ \\
\hline DIVERGÊNCIA DE OBJETIVOS & (Brouthers et al., 1995; Ozorhon et al., 2008) \\
\hline RISCO DA PARCERIA & (Brouthers et al., 1995 \\
\hline TROCA DE INFORMAÇÃO & (1reland et al., 2002) \\
\hline CONFIANÇA & (Gulati, 1998; Ireland et al., 2002) \\
\hline SOBREPOSIÇÃO DE TAREFAS & (Henneveld, 2006) \\
\hline APRENDIZAGEM & (Ariño, 2003; Gulati, 1995; Gulati \& Singh, 1998; Harrigan \& Newman, 1990; Kogut, 1988; Lyra, 2005) \\
\hline CARGA ADMINISTRATIVA & (Carvalho, 2009; Gulati, 1998; Kogut, 1988) \\
\hline AUTONOMIA & (Harrigan \& Newman, 1990; Shenhar \& Dvir, 2007) \\
\hline SATISFAÇÃO COM O PARCEIRO & (Gulati, 1998; Khanna et al., 1998) \\
\hline
\end{tabular}

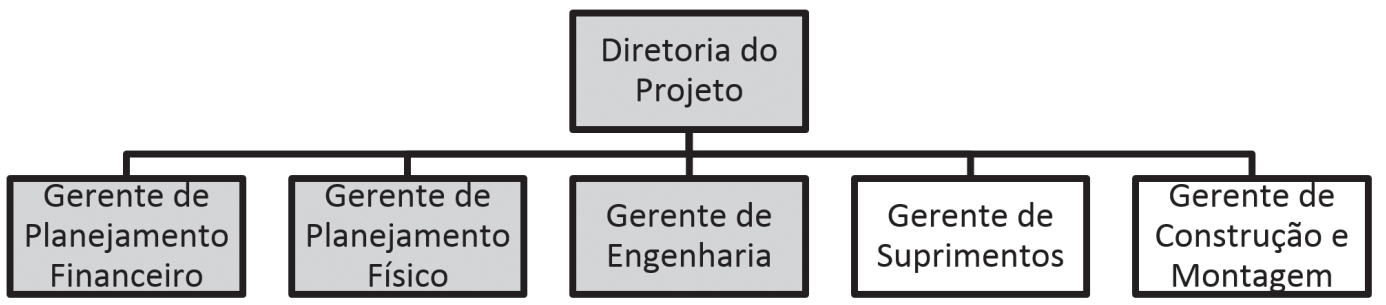

Figura 2. Posicionamento dos entrevistados na hierarquia. 
Foram selecionadas 4 pessoas por projeto (em cinza na Figura 2) que têm mais envolvimento gerencial com a parceria. Um detalhamento do perfil desses respondentes é apresentado na Tabela 3.

Apesar do Gerente de Construção e Montagem possuir influência na parceria ele não foi selecionado para participar da pesquisa pois ele normalmente é da empresa parceira a qual não temos acesso. Optou-se por não incluir o Gerente de Suprimentos, pois sua atuação mais forte é com os fornecedores.

Em alguns casos, observou-se que alguns respondentes estavam nas posições analisadas em dois ou mais projetos da amostra. Nesses casos, foi pedido ao respondente que respondesse o questionário individualmente para cada projeto. Por exemplo, nos projetos 1 e 2, a pessoa no cargo de Gerente de Engenharia também era Diretor (ou Gerente) do Projeto.

\subsection{Instrumento de pesquisa - Questionário}

0 questionário foi desenvolvido com base no referencial teórico contendo 17 variáveis (ver Tabela 2). As assertivas foram elaboradas, utilizando-se a escala Likert de 5 níveis (ver Tabela 4).

A variável sucesso foi operacionalizada conforme a tríplice restrição, ou triângulo de ferro, sugerida por vários autores como Belassi \& Tukel (1996) e Hatush \& Skitmore (1997) e Atkinson (1999), além de uma questão relacionada ao resultado geral do projeto.

Além disso, para analisar a possível interferência da variável tipo de projeto, adotou-se no instrumento de pesquisa dois parâmetros, o grau de complexidade de projetos, grau de novidade (Clark \& Fujimoto, 1991; Shenhar et al., 2005; Shenhar \& Dvir, 2007) e dispersão geográfica (Evaristo \& van Fenema, 1999). Tanto as quatro assertivas de sucesso (prazo, custo, qualidade e resultado geral), como as duas assertivas de tipo (complexidade, novidade e dispersão geográfica) foram elaboradas com base na literatura de referência, utilizando a mesma escala Likert de 5 níveis, das questões sobre alianças.

Foi utilizada uma pesquisa eletrônica através da internet ("Internet Survey") de fácil preenchimento. Essa ferramenta foi escolhida, pois é bastante eficiente em relação ao custo e prazo de implementação e possui grande interatividade e facilidade de uso
(Zikmund, 2003). A ferramenta eletrônica escolhida para realizar essa pesquisa é de livre acesso e pode ser utilizada via internet (http://docs.google.com).

0 questionário foi consolidado junto ao PMO da empresa que apoiou com críticas e sugestões. Na sequência, foram realizados testes para validar o questionário. Inicialmente se testou a plataforma on-line para verificar se seus resultados eram consistentes. Depois, iniciou-se uma rodada de teste com alguns funcionários não ligados à pesquisa que concordaram em dar suas opiniões sobre a ferramenta e a pesquisa. Baseado em suas opiniões, o questionário foi devidamente ajustado para facilitar a compreensão dos conceitos e de sua utilização.

Como forma de maximizar o número de respostas, a diretoria da empresa, em uma atitude de apoio a este estudo, enviou um e-mail para cada um dos respondentes, apresentando o projeto e fazendo o convite para a participação dos envolvidos. Logo em seguida, foi enviado, para cada um dos respondentes um e-mail que convidava o respondente a participar da pesquisa. Neste e-mail estava identificado o projeto sobre o qual o respondente deveria responder o questionário.

Os resultados do levantamento foram analisados a partir dos dados de estatística descritiva e a partir de duas técnicas estatísticas: o teste de mediana de Mood (Mood Median Test) e a análise das correlações.

0 teste não paramétrico de mediana de Mood visa testar a igualdade de medianas de duas ou mais populações e é recomendado para escalas do tipo utilizado. As análises foram elaboradas no software MINITAB. 0 teste de mediana de Mood foi realizado com dois objetivos. Primeiro, verificou-se a relação entre as variáveis relacionadas às parcerias (ver Tabela 2) e o resultado dos projetos, considerando o triângulo de ferro, prazo, custo e qualidade, bem como o resultado geral dos projetos, considerando uma perspectiva mais estratégica; a escala de likert foi convertida para duas posições Sucesso (escalas 4 e 5) e Fracasso para os demais valores. Segundo, relacionaram-se as variáveis de parcerias com as variáveis contextuais do projeto como complexidade, grau de novidade e dispersão geográfica; a escala de likert també foi convertida para duas posições Alto (escalas 4 e 5) e Baixo para os demais valores.

Tabela 3. Perfil do respondente.

\begin{tabular}{ccc}
\hline Cargo & Sigla & Função \\
\hline Diretor (ou Gerente) do Projeto & DP & Responsável Geral pelo Projeto \\
Gerente (ou Coordenador) de Planejamento Físico & GP Físico & Responsável pelo Prazo do Projeto \\
Gerente (ou Coordenador) de Planejamento Financeiro & GP Financeiro & Responsável pelo Custo do Projeto \\
Gerente (ou Coordenador) de Engenharia & GE & Responsável pela parte Técnica do Projeto \\
\hline
\end{tabular}




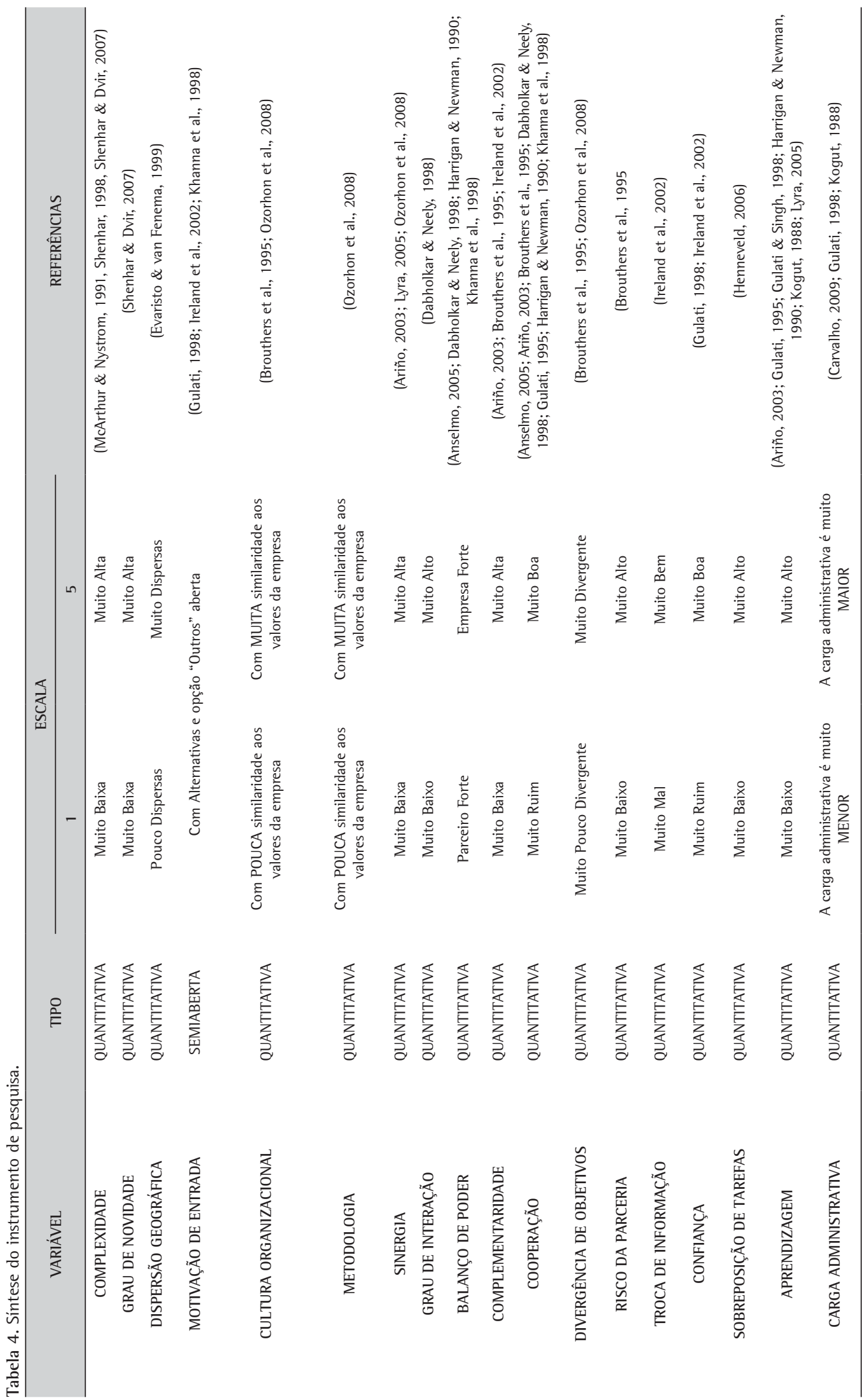




\section{Resultados da pesquisa}

0 estudo de campo foi feito em uma empresa brasileira de engenharia dedicada a prover soluções para vários setores da economia. Foi fundada na década de 60 e atua nos setores de energia elétrica, química e petroquímica, mineração e metalurgia, óleo e gás, indústrias de processo, logística e transportes e meio ambiente desenvolvendo e implementando soluções com base em suas competências fundamentais de engenharia, gerenciamento, suprimentos, construção e montagem. A empresa oferece serviços profissionais de consultoria, projetos de engenharia, estudos de viabilidade ou gerenciamento de projetos. Além disso, oferece soluções de integração de sistemas e fornecimentos e projetos via contratação tipo EPC/EPCM. A empresa teve receita de 400 milhões em 2007 e possui longa experiência em gerenciamento de projetos tendo como referência os conceitos estabelecidos pelo PMI ("Project Management Institute"). Possui experiência internacional em vários países como Estados Unidos, Suécia, China e Argentina. É presença constante nos rankings das melhores empresas para se trabalhar e das empresas modelo em sustentabilidade empresarial, além disso, já recebeu o Prêmio Nacional da Qualidade. Para manter suas competências essenciais, foram criados os centros de competência que atuam de forma horizontal em todos os projetos, buscando sempre a excelência e a busca de melhores práticas. Neste trabalho, em especial o centro de competência de gerenciamento de projetos teve papel fundamental no fornecimento de informações e acompanhamento da pesquisa.

\subsection{Projetos}

Foi feita uma seleção de projetos a serem estudados em função de uma base inicial de 99 projetos. Destes, 22 indicaram algum tipo de parceria, dos quais 11 foram selecionados para compor a amostra do trabalho, por conter parcerias recentes o suficiente para que os respondentes se recordassem de suas características (ver Tabela 5).

0 projeto 1 está em andamento atualmente na empresa do tipo Estimativa de Viabilidade Técnico-Econômica (EVTE) de um complexo industrial químico. Está no escopo do projeto a análise e verificação das tecnologias, orçamentação e a consolidação e desenvolvimento da engenharia básica necessária para o desenvolvimento do empreendimento.

0 projeto 2 é a EVTE do projeto 3.0 projeto 2 contém a consolidação da engenharia básica, cotação de alguns equipamentos, estimativa do investimento total e prazo para implantação de um projeto de um complexo industrial químico (Projeto 3).

Assim que esse projeto foi concluído, o cliente contratou também o Projeto do empreendimento que foi estimado (Projeto 3). Este é um EPC típico contendo todas as fases de engenharia, suprimentos, construção, montagem eletromecânica e comissionamento de um complexo químico. Grande parte da equipe envolvida é a mesma da realização do Projeto 2. Além disso, os projetos 1, 2 e 3 são para um mesmo cliente.

Os projetos 4, 5, 6, 8 e 10 são EPCs típicos de construção de unidades petroquímicas adicionais em refinarias. 0 projeto 11 também é um EPC típico, só que em um terminal petroquímico.

0 projeto 7 consiste em um EPC de construção e instalação de uma unidade geradora de energia consistindo de duas turbinas a vapor. Uma diferença deste para os EPCs típicos da empresa é que cada uma das empresas tinha um escopo específico no projeto. A empresa ficou responsável pelo gerenciamento, pelas obras civis, montagem eletromecânica e alguns itens de suprimento. 0 parceiro forneceu as turbinas e equipamentos elétricos relacionados.

0 Projeto 9 consiste na instalação de um trem turbo-gerador-soprador em uma usina e distribuição por dutos sobre pipe-rack do ar soprado para alimentação

Tabela 5. Caracterização dos projetos analisados.

\begin{tabular}{|c|c|c|c|c|c|c|}
\hline PROJETOS & STATUS & TIPO & $\begin{array}{c}\text { PRAZO } \\
\text { (Meses) }\end{array}$ & PORTE & CLIENTE & DISTÂNCIA (Km) \\
\hline P 1 & ATIVA & EVTE & 12 & MÉD1O & CLIENTE 1 & 500 \\
\hline P 2 & ENCERRADO & EVTE & 13 & MÉDIO & CLIENTE 1 & 500 \\
\hline P 3 & ATIVA & EPC & 24 & GRANDE & CLIENTE 1 & 500 \\
\hline P 4 & ATIVA & EPC & 44 & GRANDE & CLIENTE 2 & 100 \\
\hline P 5 & ATIVA & EPC & 44 & GRANDE & CLIENTE 3 & 400 \\
\hline P 6 & ATIVA & EPC & 30 & GRANDE & CLIENTE 4 & 1500 \\
\hline P 7 & ENCERRADO & EPC & 28 & GRANDE & CLIENTE 5 & 1300 \\
\hline P 8 & ATIVA & EPC & 24 & GRANDE & CLIENTE 6 & 450 \\
\hline P 9 & ENCERRADO & EP & 26 & GRANDE & CLIENTE 7 & 370 \\
\hline P 10 & ATIVA & EPC & 34 & GRANDE & CLIENTE 2 & 100 \\
\hline P 11 & ENCERRADO & EPC & 24 & GRANDE & CLIENTE 8 & 900 \\
\hline
\end{tabular}


dos 2 altos-fornos da usina. 0 escopo continha o fornecimento de engenharia, projeto básico e detalhado, materiais, equipamentos. No que diz respeito a suprimentos, a empresa só tinha responsabilidade na entrega deles no site de fornecimento. Sendo assim, esse projeto se configura não como um EPC, mas como um EP, pois só há engenharia e suprimentos.

0 porte dos projetos na empresa é considerado pequeno quando a receita operacional é menor do que 4 milhões de reais. É considerado médio de 4 até 40 milhões e grande acima de 40 milhões de reais. Sendo assim, é possível perceber que o porte dos projetos analisados é grande, envolvendo grandes quantias e isso impacta diretamente nos resultados da pesquisa conforme será discutido.

\subsection{Parceiros}

Os projetos analisados envolvem parceria com cinco empresas. Três parceiros são do setor de construção, um da área de petróleo e gás e um da área de tecnologia. As principais competências dos parceiros estão sintetizadas na Tabela 6 .

0 parceiro A é uma construtora nacional que presta serviços integrados de engenharia, suprimento, construção, montagem e gerenciamento de obras civis, industriais. Durante sua trajetória, executou obras nas áreas de construção de edifícios, barragens, usinas térmicas, hidrelétricas e siderúrgicas, petroquímicas, refinarias, metrôs, rodovias, ferrovias, pontes, portos e aeroportos, sendo posicionada como uma das maiores construtoras do mundo.

0 parceiro B é uma construtora nacional que atua em vários mercados inclusive no mercado de grandes obras. É uma das líderes no mercado brasileiro de construção e atua em 12 países nas áreas de energia, transporte e mineração, obras públicas, saneamento e indústria.

0 parceiro C é uma construtora multinacional de origem europeia que atua no mercado de obras de grande porte há mais de 100 anos. Está presente em diversos paises da Europa, nos Estados Unidos e na América Latina. Chegou ao Brasil na década de 90 se destacando nas áreas de construção e montagem de plantas industriais e de desenvolvimento de infraestrutura, com forte presença no mercado de óleo e gás.

0 parceiro D é uma empresa nacional atuante nos segmentos de produção e processamento de petróleo e gás, petroquímica, geração de energia, siderurgia, papel e celulose, metalurgia, construção e manutenção industrial. Atua no setor de EPC, concentrando suas atividades no gerenciamento, construção, montagem e manutenção, a empresa tem em seu histórico a instalação de refinarias, indústrias petroquímicas e de fertilizantes. Foi uma das empresas pioneiras na área de "offshore".

0 parceiro E é uma empresa multinacional de tecnologia que está no Brasil há mais de cem anos e representa um dos maiores conglomerados de engenharia elétrica e eletrônica do País. Apresenta vários setores de atuação tendo uma vasta gama de produtos no mercado. Apresenta atualmente por volta de 9000 colaboradores.

\subsection{Levantamento com os stakeholders do projeto}

0 Apêndice 1 apresenta a síntese dos resultados por questão, detalhando o número de respondentes, média, moda, mediana, desvio padrão e variância. Nesse tópico, discutiremos as questões relacionadas à motivação, coopeticão e poder de barganha, e dinâmica da parceria. Essas análises utilizaram estudo de correlação, análise de variância (ANOVA), tendo como pano de fundo os modelos discutidos no quadro teórico.

\subsubsection{Motivação de entrada e aprendizagem}

Na questão sobre a motivação de entrada, havia um conjunto de alternativas extraídas do quadro teórico, além da opção livre "Outros”. A compilação dos resultados deste item "Outros" pôde ser agrupada em 3 novas respostas: "Solicitação do Cliente", "Somente EPCistas completos podem entrar na concorrência” e

Tabela 6. Competências dos parceiros.

\begin{tabular}{|c|c|c|c|c|}
\hline & ENGENHARIA & SUPRIMENTOS & $\begin{array}{l}\text { CONSTRUÇÃO E } \\
\text { MONTAGEM }\end{array}$ & TECNOLOGIA \\
\hline Empresa & +++ & +++ & ++ & - \\
\hline PARCEIRO A & +++ & +++ & +++ & - \\
\hline PARCEIRO B & ++ & +++ & +++ & - \\
\hline PARCEIRO C & + & + & +++ & - \\
\hline PARCEIRO D & + & + & +++ & - \\
\hline PARCEIRO E & - & - & - & +++ \\
\hline
\end{tabular}

Legenda: - Não Possui / + Fraco / ++ Médio / +++ Destaque. 
"Melhorar a Parceria". Assim, o número de respostas obtidas nessa pergunta para cada uma de suas opções, incluindo as novas geradas pelo item "Outros" estão apresentadas na Tabela 7.

A principal motivação de entrada em parcerias foi à divisão de custos e riscos, o que é bem compreensível em função do porte dos projetos da empresa, que muitas vezes têm um valor financeiro maior do que o faturamento anual da empresa.

Um ponto que chamou a atenção é o surgimento de 11 respostas dizendo que foi uma imposição do cliente. Nesses 11, ainda podem ser adicionados mais 2 comentários referentes a somente EPCistas completos poderem entrar nas concorrências, o que acaba sendo também uma exigência do cliente. Tem-se, então, 13 respostas indicando essa motivação.

Questões relacionadas a aprendizado, inovação e melhoria de parcerias foram pouco assinaladas pelos respondentes. Os resultados obtidos na pergunta sobre "aprendizagem" apontam para um grau de aprendizado intermediário. Sendo que 24 das 41 respostas (58\%) foram exatamente no nível intermediário (3).

Nas entrevistas, foi possível perceber que, na maioria das parcerias realizadas, o principal ponto de aprendizado para a empresa estudada foi o aprendizado de construção e montagem (C\&M), que é uma lacuna em face de muitas das empresas parceiras que possuem esse know-how mais desenvolvido. Em C\&M, foram citadas como pontos de aprendizagem a forma de acesso à mão de obra e ao gerenciamento. Por outro lado, a empresa foi fonte de aprendizado dos parceiros, em aspectos relacionados ao sistema de gerenciamento de projetos da empresa, tais como orçamentação, gerenciamento, elaboração de cronogramas e comprometimento com o resultado.

Além disso, outros pontos de aprendizado destacados foram: relacionamento com 3 parceiros, o aprendizado tecnológico, técnico e gerencial e aprendizado de novos mercados.
Os resultados obtidos indicam um perfil diferente de parcerias, pois as parcerias da empresa possuem uma visão de curto prazo e com um compartilhamento parcial de conhecimentos com o objetivo apenas de compartilhar os custos e riscos e utilizar as competências do parceiro para um propósito específico, sem necessariamente aprendê-las.

É possivel perceber que a escolha de empresas parceiras com foco em construção e montagem se alinha com as motivações de entrada "solicitação do cliente" e do cliente "somente aceitar EPCistas completos".

Sendo assim, fica a sensação de que a empresa tem entrado nas parcerias ad hoc, por demanda de mercado. Assim, acaba por não se preocupar na manutenção e no correto desenvolvimento dessas parcerias, o que limita as possibilidades de aprendizado, pois sem interesse a longo prazo não há compartilhamento de competências e conhecimentos que poderiam ser absorvidos pelos parceiros envolvidos (Lorange et al., 1992).

\subsubsection{Cooperação}

Para se analisar a interdependência entre os parceiros nos projetos estudados é possível realizar uma simplificação do cubo da interdependência (Dabholkar \& Neely, 1998). Como todas as parcerias analisadas possuem um objetivo de curto prazo, pois todas elas são parcerias contratuais e terminam com o final do contrato, o eixo da variável "prazo" (curto e longo) foi retirado da análise, que se restringiu aos quatro quadrantes da Figura 3.

Para realizar a análise de interdependência, foram utilizadas as questões de "cooperação" para o eixo horizontal e de "balanço de poder" para o eixo vertical.

É possível perceber que a maioria dos projetos da empresa está levemente orientada à cooperação. A exceção é o Projeto 4 que apresenta características

Tabela 7. Motivação de entrada.

\begin{tabular}{ccc}
\hline Motivação & $\#$ & \\
Divisão de custos e riscos & 30 & PROPOSTO \\
Solicitação do Cliente & 11 & NOVO \\
Acesso a novos Projetos & 10 & PROPOSTO \\
Compartilhamento de vantagens produtivas & 9 & PROPOSTO \\
Compartilhamento de tecnologia complementar & 9 & PROPOSTO \\
Acesso a novos mercados & 8 & PROPOSTO \\
Reduzir o tempo para a inovação através do aprendizado & 4 & PROPOSTO \\
Acesso a recursos financeiros & 2 & PROPOSTO \\
Someno & NOVO \\
Agrupar desenvolvimento de nova tecnologia & 2 & PROPOSTO \\
TOTAL & 2 & 1 \\
\hline
\end{tabular}


significativas de competição. 0 projeto 4 apresenta uma média muito baixa $(1,5)$ para a variável "cultura organizacional”, bem como para a variável "confiança” $(2,50)$. Quando avaliamos a divergência de objetivos vê-se que a divergência de objetivos também é mais alta $(3,75)$ no projeto 4 .

Observando-se os dados referentes à comparação entre a metodologia em Gestão de Projetos (GP) da empresa e dos parceiros, observa-se um comportamento consensual entre os respondentes de que há discrepâncias entre as metodologias adotadas.

0 perfil das empresas parceiras é a principal causa dessa diferença, pois são empresas de construção, focadas na execução da obra. A empresa estudada por sua vez, é uma empresa essencialmente de engenharia e gerenciamento. Assim, é natural que a empresa tenha a metodologia de GP com diferenças em relação aos parceiros.

É interessante observar que o projeto 5, o mais orientado à colaboração, apresenta uma baixa divergência de objetivos $(1,75)$, alta similaridade em metodologia de GP. Mais uma vez, o projeto 5 se

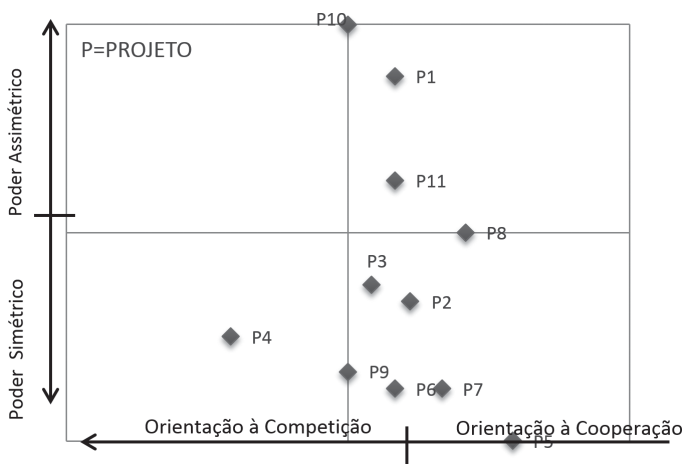

Figura 3. Aplicação do Cubo da Interdependência. mostra com características distintas, inclusive em relação a outros projetos com o mesmo parceiro (B), pois houve um esforço de homogeneização das metodologias entre os parceiros envolvidos.

Observando os resultados do questionário, a carga administrativa apresentou apenas um leve aumento em relação aos projetos individuais da empresa e, na visão dos respondentes, a sobreposição de tarefas ocorre pouco, indicando uma boa coordenação entre os parceiros (Henneveld, 2006).

A complementaridade entre os parceiros é fundamental para o desenvolvimento sadio de uma aliança (Wu et al., 2009). Ao observar os valores indicados pelos respondentes para a variável "complementaridade" é possivel afirmar que a complementaridade entre os envolvidos é alta (média geral de 3,69). Esse resultado é condizente com a Tabela 4, pois as empresas envolvidas se complementam no que concerne a três competências: execução de construção civil (parceiros A, B, C essencialmente), tecnologia (parceiro E) e engenharia e gerenciamento (empresa).

Utilizando as médias da variável "balanço de poder", foi comparado o poder de barganha da empresa estudada e do parceiro dominante (líder) por projeto (ver Figura 4). Nos projetos 1, 10 e 11 há grande assimetria de poder, enquanto no projeto 11 é a empresa estudada que possui o poder. Nos projetos 1 e 10 são os parceiros A e B que detêm o poder, respectivamente. 0 projeto 5 é o mais balanceado.

É possivel perceber que o poder está altamente relacionado com quem é líder contratual do projeto. Para comprovar essa hipótese, foi realizada a análise de variância (ANOVA) para a diferença nas médias da variável "balanço de poder" em função do líder do projeto, que apontaram para diferença significativa

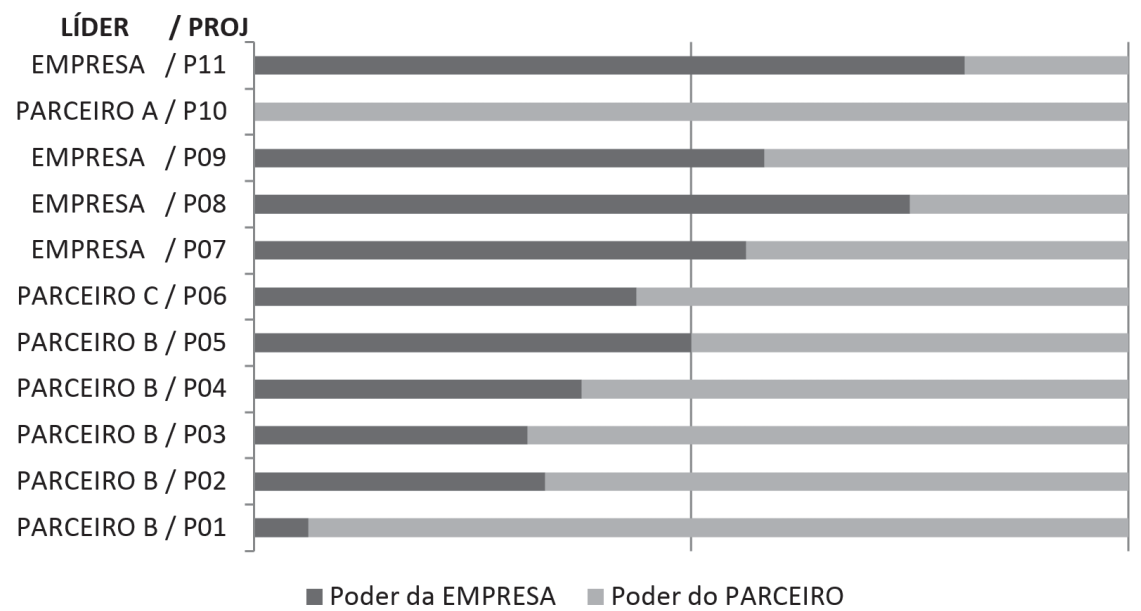

Figura 4. Balanço de força das parcerias. 
( $\mathrm{p}<0,05)$ para a média da variável "balanço de poder" em função do líder do projeto.

Analisando as médias das respostas da questão de autonomia por categoria de respondente, é possivel perceber que todos sentem o impacto da parceria em sua autonomia de trabalho. O DP é o mais impactado. 0 poder e a autonomia estão relacionados, pois quem detém maior poder costuma também deter maior autonomia em seu trabalho (Harrigan \& Newman, 1990).

\subsubsection{Dinâmica da parceria}

Analisar a dinâmica organizacional é compreender como a estrutura das organizações e suas interfaces influenciam no resultado da parceria (Lyra, 2005). Para analisar essa interação entre os parceiros, foi utilizada uma adaptação do diagrama de Ragan \&

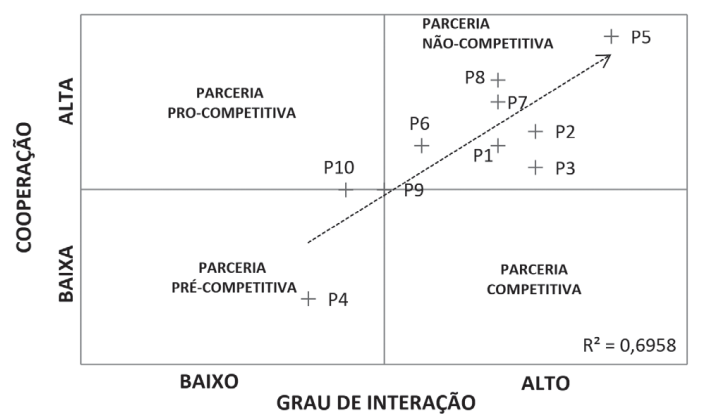

Figura 5. Diagrama de Cooperação e Interação.
Yoshino (1996) (ver Figura 5). Foram utilizadas as médias das variáveis "cooperação" e "grau de interação" por projeto para realização do diagrama.

É possível observar que há correlação significativa $(R>0,6)$ entre as variáveis envolvidas. lsso mostra que quanto maior o grau de interação entre os parceiros, maior o nível cooperação.

A literatura sugere vários fatores que impactam o sucesso da parceria, conforme quadro teórico. Na pesquisa de campo, a análise de correlação entre as variáveis pesquisadas permitiu estabelecer uma sintese dos principais fatores que estão estatisticamente correlacionados positivamente entre si em todas as direções (os valores na Figura 6 são o coeficiente de correlação, utilizando como critério de corte $0,60)$. Esses cinco fatores críticos para a dinâmica de funcionamento da parceria são: cooperação, confiança, troca de informações, sinergia e integração.

Os dados obtidos não mostram diferenças significativas entre as categorias de respondentes ou entre projetos mostrando que essa é uma visão consolidada na empresa.

\subsection{Recomendações para melhorar as relações em projetos complexos}

A triangulação da revisão de literatura com as evidências de campo permitiu destacar alguns fatores em alianças para o desenvolvimento de projetos complexos do tipo EPC. Das 17 variáveis analisadas extraídas da literatura (ver Tabela 2), cinco apresentaram

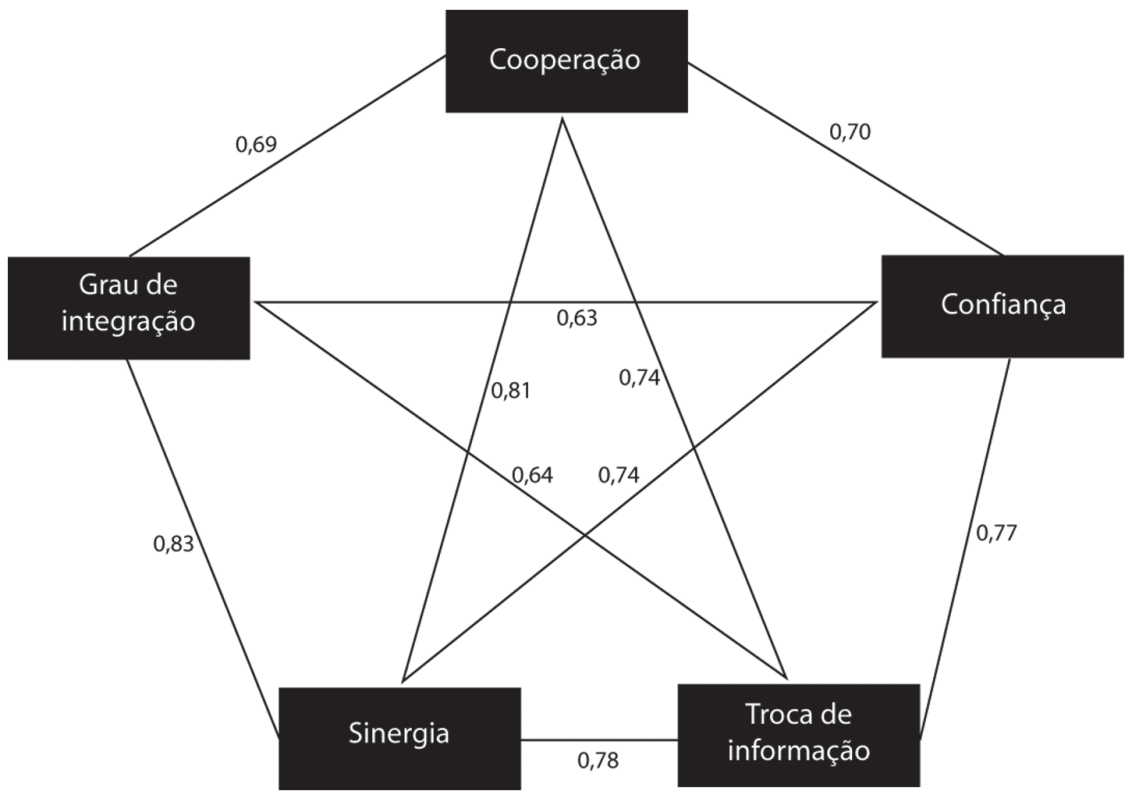

Figura 6. Variáveis de interação. 
Tabela 8. Relacionamento entre variáveis do estudo.

\begin{tabular}{|c|c|c|c|c|c|c|c|c|}
\hline & \multirow[b]{2}{*}{ VARIÁVEL } & \multicolumn{7}{|c|}{ Mediana de Mood (valor de p) } \\
\hline & & 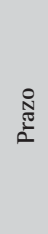 & $\frac{0}{\tilde{J}}$ & $\frac{\frac{\pi}{0}}{\frac{\pi}{0}}$ & 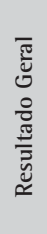 & 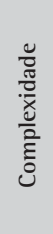 & $\begin{array}{l}\frac{\pi}{0} \\
\frac{\pi}{0} \\
\frac{0}{2} \\
z\end{array}$ & 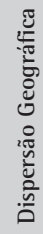 \\
\hline \multirow{12}{*}{ 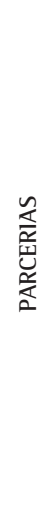 } & DEFINIÇÃO DOS OBJETIVOS DO PROJETO & & & & & & & \\
\hline & CULTURA ORGANIZACIONAL & & & & & & & \\
\hline & SINERGIA & & & & & & & \\
\hline & GRAU DE INTERAÇÃO & & & & & & & \\
\hline & BALANÇO DE PODER & & & & & & & \\
\hline & COMPLEMENTARIDADE & & & & & & & \\
\hline & COOPERAÇÃO & & & & & & & \\
\hline & TROCA DE INFORMAÇÃO & & & & & & & \\
\hline & CONFIANÇA & & & & & & & \\
\hline & APRENDIZAGEM & & & & & & & \\
\hline & CARGA ADMINISTRATIVA & & & & & & & \\
\hline & AUTONOMIA & & & & & & & \\
\hline
\end{tabular}

99\% de confiança $\quad 95 \%$ de confiança $\quad$ 90\% de confiança

forte correlação: cooperação, confiança, troca de informações, sinergia, grau de integração.

Além disso, o teste de Mood permitiu verificar que, das 17 variáveis, 12 tiveram relação com o resultado do projeto, em alguma das dimensões estudadas ou com as variáveis contextuais analisadas, como ilustra a Tabela 8 e detalha o Apêndice 1.

As dimensões mais relacionadas com eficiência (prazo, custo e qualidade) todas apresentaram correlação significativa com a variável carga administrativa. lsso significa que os projetos em parceria que obtiveram sucesso tiveram que arcar com uma carga administrativa maior. A dimensão de custos mostrou-se também relacionada à cooperação entre os parceiros, enquanto a dimensão tempo, relacionou-se com similaridade entre as culturas organizacionais dos parceiros. A dimensão de sucesso mais impactada pelas variáveis de parceria foi a qualidade, que se relacionou com 4: carga administrativa, complementaridade, troca de informações e definição dos objetivos do projeto.

Observa-se também que quanto maior a dispersão geográfica maior a necessidade de trabalhar variáveis relacionadas à parceria (ver Tabela 8 ).

\section{Conclusões}

Este estudo apontou vários insights que merecem ser analisados mais profundamente. Há indícios de que boa parte das alianças feitas nesses projetos tem caráter ad hoc, com relacionamentos baseados em uma frágil cooperação com visão de curto prazo. Os parceiros se unem apenas para atender a exigências de clientes, com poder de barganha elevado, que demandam a formação de consórcios para minimizar os riscos de projetos complexos e facilitar a coordenação.

A escolha dos parceiros é feita caso a caso, não havendo visão a longo prazo. Assim, em cada projeto há um novo desenvolvimento de parceria gerando um grande retrabalho, na construção do relacionamento e da dinâmica de trabalho. Em alguns projetos as parcerias foram induzidas pelos clientes.

Esse achado traz implicações para a teoria, pois a literatura sugere que o desenvolvimento de alianças estratégicas se dá em uma perspectiva estratégica, em que se buscam aprendizagem e novas competências (Harrigan \& Newman, 1990; Ireland et al., 2002; Kogut, 1988). De fato, os resultados apontam para a perspectiva de diminuir as barreiras de entrada em um mercado, o que merece estudos mais detalhados neste contexto. Além disso, há lacuna de estudos em alianças puxadas pelo mercado (market pulh), o que demonstra ser relevante no contexto de alianças em projetos o que as distingue das alianças no contexto organizacional.

Por outro lado, as empresas parceiras estudadas apresentam grande complementaridade, mas diferem em relação à cultura organizacional como sugerem diversos autores (Doz \& Hamel, 1998, Wu et al.; 2009). 
Vale destacar que são parcerias não competitivas (Ragan \& Yoshino, 1996).

A escolha desses parceiros hoje é feita caso a caso, não havendo visão a longo prazo. Assim, em cada projeto há um novo desenvolvimento de parceria gerando um grande retrabalho. Apesar de não haver evidências de um processo formal de seleção de parceiros (El-Sawalhi et al., 2007), a empresa no geral se relaciona bem e está satisfeita com seus parceiros.

A empresa realiza parcerias principalmente porque necessita, por solicitação do cliente (mercado), realizar o EPC completo, não podendo subcontratar a construção e montagem como fazia habitualmente. Então, acaba tendo que se aliar a parceiros que possuam construção e montagem. Esses parceiros por seu porte e força se impõem fortemente na parceria e no projeto, pelo poder de barganha (Khanna et al., 1998; Dabholkar \& Neely, 1998).

Outro aspecto relevante foi o mapeamento de cinco fatores fortemente correlacionados para a dinâmica da parceria: cooperação, confiança, troca de informações, sinergia e integração. A forte correlação entre estes aspectos reforça o quadro teórico, bem como sugere prioridades no âmbito organizacional. 0 ambiente da empresa é propício para o desenvolvimento de parcerias estratégicas uma vez que esses fatores estão presentes e sugerem que a empresa poderia desenvolver parcerias de longo prazo, visando o aprendizado e compartilhamento de recursos entre as empresas, gerando melhores resultados nos projetos (Kogut, 1988). Assim, a consolidação de parcerias, caso a pressão de mercado se intensifique, demandando projetos em parceria, fica aberta uma boa possibilidade de uma boa estratégia de adaptação (Hoffmann, 2007). Os distintos fatores relacionados com parceria têm impacto no resultado dos projetos, bem como os aspectos contextuais como dispersão geográfica, complexidade de grau de novidade do projeto.

Este estudo apresenta algumas limitações inerentes ao método de pesquisa adotado. Trata-se de um estudo em uma única empresa, o que condiciona os resultados ao contexto da empresa de engenharia analisada, limitando generalizações. Além disso, foram estudados projetos do tipo EPC, o que condiciona os resultados ao contexto desse tipo de projeto, o que pode também limitar as generalizações para outros tipos de projetos complexos. Ajuda a mitigar essa limitação o fato de várias empresas líderes em diversos setores, como construção e tecnologia (ver Tabela 6), terem feito parte deste estudo, na figura dos parceiros dos projetos EPC analisados, o que remete a outros contextos organizacionais e setoriais. Desta forma, é relevante explorar esses resultados em outros contextos em uma agenda futura de estudos.
Na parte quantitativa, as questões foram baseadas na percepção dos respondentes, o que traz um viés para a análise. No entanto, os dados foram triangulados com os relatórios de desempenho e a análise em profundidade dos documentos dos 11 projetos para mitigar esse viés, além de contar com profissionais de larga experiência com empreendimentos do tipo EPC na amostra.

\section{Agradecimentos}

Agradecemos ao CNPq o apoio recebido.

\section{Referências}

Albertin, E. V., \& Amaral, D. C. (2010). Contexto da parceria como qualificador da gestão de projetos universidade-empresa. Produção, 20(2), 224-236. http://dx.doi.org/10.1590/ S0103-65132010005000033.

Amato Neto, J. (2000). Redes de cooperação produtiva e clusters regionais. São Paulo: Atlas.

Anselmo, J. L. (2005). Gerenciamento de projetos em redes de organizações (Dissertação de mestrado). Faculdade de Economia, Administração e Ciências Contábeis, Universidade de São Paulo, São Paulo.

Ariño, A. (2003). Measures of strategic alliance performance: an analysis of construct validity. Journal of International Business Studies, 34(1), 66-79. http://dx.doi.org/10.1057/ palgrave.jibs.8400005.

Ariño, A., \& de la Torre, J. (1998). Learning from failure: towards an evolutionary model of collaborative ventures. Organization Science, 9(3), 306-325. http://dx.doi. org/10.1287/orsc.9.3.306.

Assalim, L., \& Almeida, M. F. L. (2013). Conformity assessment as a tool for organizational learning in large engineering and construction projects. Journal of Technology Management and Innovation, 8, 37-48.

Atkinson, R. (1999). Project management: cost, time and quality, two best guesses and a phenomenon, its time to accept other success criteria. International Journal of Project Management, 17(6), 337-342. http://dx.doi.org/10.1016/ S0263-7863(98)00069-6.

Belassi, W., \& Tukel, O. (1996). A new framework for determining critical success/failure factors in projects. International Journal of Project Management, 14(3), 141-151. http:// dx.doi.org/10.1016/0263-7863(95)00064-X.

Brouthers, K. D., Brouthers, L. E., \& Wilkinson, T. J. (1995). Strategic alliances: choose your partners. Long Range Planning, 28(3), 18-25. http://dx.doi.org/10.1016/00246301(95)00008-7.

Carvalho, M. M. (2009). Inovação: estratégias e comunidades de conhecimento. São Paulo: Atlas.

Clark, K. B., \& Fujimoto, T. (1991). Product development performance: strategy, organization, and management in the world auto industry. Boston: Harvard Business School Press.

Dabholkar, P. A., \& Neely, S. M. (1998). Managing interdependency: a taxonomy for business-to-business relationships. Journal of Business and Industrial Marketing, 13(6), 439-460. http://dx.doi.org/10.1108/08858629810246797. 
De Britto Pires, A. M., Lima Cruz Teixeira, F., Hastenreiter Filho, H. N., \& Góes Oliveira, S. R. (2013). The challenge of building effective hybrid organizations in Brazil. Journal on Chain and Network Science, 13(1), 83-97. http://dx.doi. org/10.3920/JCNS2013.x223.

Doz, Y. L., \& Hamel, G. (1998). Alliance advantage: the art of creating value through partnering. Massachusetts: Harvard Business Scholl Press.

Dussauge, P., Garrette, B., \& Mitchel, W. (2004). Asymmetric performance: the market share impact of scale and link alliances in the global auto industry. Strategic Management Journal, 25(7), 701-711. http://dx.doi.org/10.1002/smj.416.

El-Sawalhi, N., Eaton, D., \& Rustom, R. (2007). Contractorprequalification model: state-of-the-art. International Journal of Project Management, 25(5), 465-474. http://dx.doi. org/10.1016/j.jproman.2006.11.011.

Evaristo, R., \& van Fenema, P. C. V. (1999). A typology of project management: emergence and evolution of new forms. International Journal of Project Management, 17(5), 275281. http://dx.doi.org/10.1016/S0263-7863(98)00041-6.

Guedes, R., Castaño, A. D., \& Pentenado, J. F. A. (2008). Contratos de aliança em projetos industriais. Mundo Project Management, Abril/Maio.

Guerrini, F. M., \& Vergna, J. R. G. (2011). Um modelo de atores e recursos para redes de cooperação entre empresas em obras de edificações. Produção, 21(1), 14-26.

Gulati, R. (1995). Social structure and alliance formation patterns: a longitudinal analysis. Administrative Science Quarterly, 4O(4), 619-655. http://dx.doi.org/10.2307/2393756.

Gulati, R. (1998). Alliances and networks. Strategic Management Journal, 19(4), 293-317. http://dx.doi.org/10.1002/(SICI)10970266(199804) 19:4<293::AID-SMJ982>3.0.CO;2-M.

Gulati, R., \& Singh, H. (1998). The architecture of cooperation costs and apropriation concerns in strategic alliances. Administrative Science Quarterly, 43, 781-814. http:// dx.doi.org/10.2307/2393616.

Harrigan, K. R., \& Newman, W. H. (1990). Bases of Interorganizational Co-operation: Propensity, Power, Persistence. Journal of Management Studies, 27(4), 417-434. http://dx.doi. org/10.1111/j.1467-6486.1990.tb00255.x.

Hatush, Z., \& Skitmore, M. (1997). Evaluating contractor prequalification data: selection criteria and project success factors. Construction Management and Economics, 15(2), 129-147. http://dx.doi.org/10.1080/01446199700000002.

Henneveld, M. (2006). Alliance contracting - removing the boundaries for infrastructure delivery. In Proceedings of the Annual Conference of the Transportation Association of Canada, Prince Edward lsland. Recuperado em 10 de junho de 2007, de http://www.tac-atc.ca/english/pdf/ conf2006/s001/henneveld.pdf

Hoffmann, W. H. (2007). Strategies for managing a portifolio of alliances. Strategic Management Journal, 28(8), 827856. http://dx.doi.org/10.1002/smj.607.

Holmberg, S. R., \& Cummings, J. L. (2009). Building successful strategic alliances: A strategic process and analytical tool for selecting alliance partners. Long Range Planning, 42(2), 164-193. http://dx.doi.org/10.1016/j.lrp.2009.01.004.

Ireland, R. D., Hitt, M. A., \& Vaidyanath, D. (2002). Alliance management as a source of competitive advantage. Journal of Management, 28(3), 413-446. http://dx.doi. org/10.1177/014920630202800308.
Khanna, T., Gulati, R., \& Nohria, N. (1998). The Dinamics of Learning Alliances:Competition, Cooperation, and Relative Scope. Strategic Management Journal, 19(3), 193-210. http:// dx.doi.org/10.1002/(SICl)1097-0266(199803)19:3<193::AID$\mathrm{SMJ949>3.0.CO;2-C.}$

Kogut, B. (1988). Joint ventures - theoretical and empirical perspectives. Strategic Management Journal, 9(4), 319-332. http://dx.doi.org/10.1002/smj.4250090403.

Levy, M., Loebbecke, C., \& Powell, P. (2003). SMEs, co-opetition and knowledge sharing: the role of information systems. European Journal of Information Systems, 12(1), 3-17. http://dx.doi.org/10.1057/palgrave.ejis.3000439.

Loots, P., \& Henchie, N. (2007). Worlds apart: EPC and EPCM contracts: risk issues and allocation. International Law Review, 27(1), 252-270.

Lorange, P., Roos, J., \& Bronn, P. S. (1992). Building successful strategic alliances. Long Range Planning, 25(6), 10-17. http://dx.doi.org/10.1016/0024-6301(92)90164-W.

Lyra, R. R. (2005). Desempenho de alianças estratégicas: análise de modelos e construtos (Dissertação de mestrado). Pontifícia Universidade Católica do Rio de Janeiro, Rio de Janeiro.

Masi, D., Micheli, G. J. L., \& Cagno, E. A. (2013). Meta-model for choosing a supplier selection technique within an EPC company. Journal of Purchasing and Supply Management, 19(1), 5-15. http://dx.doi.org/10.1016/j.pursup.2012.07.002.

McArthur, A. W., \& Nystrom, P. C. (1991). Environmental dynamism, complexity, and munificence as moderators of strategy-performance relationships. Journal of Business Research, 23(4), 349-361. http://dx.doi.org/10.1016/01482963(91)90020-X.

Morris, P. W. G., \& Geraldi, J. (2011). Managing the institutional context for projects. Project Management Journal, 42(6), 20-32. http://dx.doi.org/10.1002/pmj.20271.

Narayanan, V. K., Zane, L. J., \& Kemmerer, B. (2011). The cognitive perspective in strategy: an integrative review. Journal of Management, 37(1), 305-351. http://dx.doi. org/10.1177/0149206310383986.

Ozorhon, B., Arditi, D., Dikmen, l., \& Birgonul, M. T. (2008). Effect of partner fit in international construction joint ventures. Journal of Management Engineering, 24(1), 12-20. http://dx.doi.org/10.1061/(ASCE)0742-597X(2008)24:1(12).

Pauget, B., \& Wald, A. (2013). Relational competence in complex temporary organizations: the case of a French hospital construction project network. International Journal of Project Management, 31(2), 200-211. http://dx.doi. org/10.1016/j.ijproman.2012.07.001.

Ragan, U. S., \& Yoshino, M. Y. (1996). Forging alliances: a guide to top management. The Columbia Journal of World Business, 31(3), 6-13. http://dx.doi.org/10.1016/ S0022-5428(96)90037-X.

Reame Junior, E., \& Amaral, D. C. (2012). Fatores críticos de sucesso em projetos colaborativos na indústria de máquinas agrícolas. Produção, 22(4), 696-708.

Shenhar, A. J. (1998). From theory to practice: toward a typology of project management styles. IEEE Transactions on Engineering Management, 41(1), 33-48. http://dx.doi. org/10.1109/17.658659.

Shenhar, A. J., \& Dvir, D. (2007). Reinventing project management: the diamond approach to succesful growth and innovation. Boston: Harvard Business School Press. 274 p.

Shenhar, A. J., Dvir, D., Milosevic, D., Mulenburg, J., Patanakul, P., Reilly, R., Ryan, M., Sage, A., Sauser, B., Srivannaboon, 
S., Stefanovic, J., \& Thamhain, H. (2005). Toward a NASAspecific project management framework. Engineering Management Journal, 17(4), 8-16. http://dx.doi.org/10 .1080/10429247.2005.11431667.

Sun, J., \& Zhang, P. (2011). Owner organization design for mega industrial construction projects. International Journal of Project Management, 29(7), 828-833. http://dx.doi. org/10.1016/j.ijproman.2011.04.005.

Voss, C. A., Tsikriktsis, N., \& Frohlich, M. (2002). Case research in operations management. International Journal of Operations \& Production Management, 22(2), 195-219. http://dx.doi.org/10.1108/01443570210414329.

Wittmann, C.M., Hunt, S. D., \& Arnettb, D. B. (2008). Explaining alliance success: competences, resources, relational factors, and resource-advantage teory. Industrial Marketing Management, 38(7), 743-756. http://dx.doi.org/10.1016/j. indmarman.2008.02.007.

Wu, W. Y., Shih, H.-A., \& Chan, H.-C. (2009). The analytic network process for partner selection criteria in strategic alliances. Expert Systems with Applications, 36(3), 46464653. http://dx.doi.org/10.1016/j.eswa.2008.06.049.

Zikmund, W. G. (2003). Business research methods (7. ed.). Ohio: Thomson Learning.

Zollo, M., Reuer, J. J., \& Singh, H. (2002). Interorganizational routines and performance in strategic alliances. Organization Science, 13(6), 701-713. http://dx.doi.org/10.1287/ orsc.13.6.701.503.

\section{Alliances in complex projects: a study of an EPC project \\ Abstract}

This study aims to identify critical success factors for complex projects developed in alliances between companies. The theoretical framework is grounded in concepts related to projects and partnerships that address aspects related to motivation, characterization and dynamic operation. The exploratory research was conducted in an engineering services organization, mixing methods of qualitative and quantitative research. Data were gathered from 11 projects in partnerships via interviews performed with 43 managers involved in such projects. The combination of the literature review and the field research evidence highlighted some critical success factors in the projects of Engineering, Procurement and Construction (EPC) that were developed in the alliances. The results indicate five factors that were strongly correlated: cooperation, trust, information exchange, synergy and degree of integration. Furthermore, from 17 factors, 12 were significantly related to the projects' results in some of the dimensions studied.

\section{Keywords}

Alliance. Project management. Cooperation. Complex projects. EPC. 


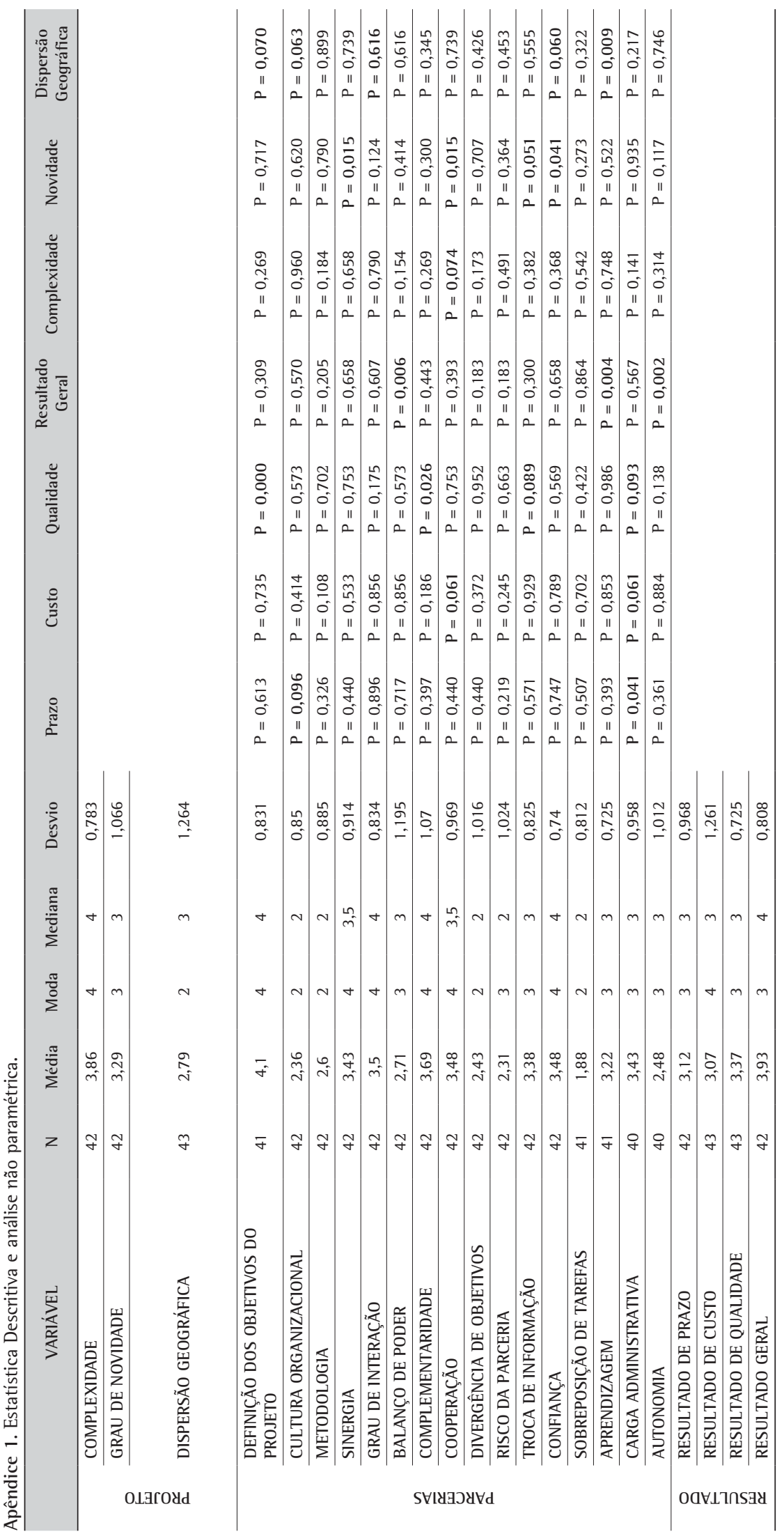

